\title{
Modulation of station rainfall over the western Pacific by the Madden- Julian oscillation
}

\author{
Adrian J. Matthews and Hoi Yee Yvonne Li \\ Schools of Environmental Sciences and Mathematics, University of East Anglia, Norwich, UK
}

Received 23 May 2005; revised 13 June 2005; accepted 23 June 2005; published 29 July 2005.

[1] Rainfall data from 140 stations in the PACRAIN network in the tropical western Pacific are analysed to assess the signal due to the Madden-Julian oscillation (MJO). During northern winter, the station rainfall difference between the wet and dry phases of the MJO is up to $6 \mathrm{~mm}$ day $^{-1}$, compared to the climatological mean value of $12 \mathrm{~mm} \mathrm{day}^{-1}$. The anomalies have a strong spatial coherence, with over $80 \%$ of the individual point station anomalies having the same sign as the large-scale rainfall anomaly, as determined by the mainly satellite-derived CMAP rainfall product. Citation: Matthews, A. J., and H. Y. Y. Li (2005), Modulation of station rainfall over the western Pacific by the Madden-Julian oscillation, Geophys. Res. Lett., 32, L14827, doi:10.1029/2005GL023595.

\section{Introduction}

[2] The Madden-Julian oscillation (MJO) is the dominant mode of intraseasonal variability in the tropical atmosphere [Madden and Julian, 1994]. It consists primarily of largescale (approximately $1000 \mathrm{~km}$ across) deep convective tropical rainfall anomalies that propagate slowly eastward from the Indian Ocean, through the maritime continent of Indonesia, and into the western Pacific, where they decay at around the date line. The time taken for one such MJO event is typically between 30 and 60 days. Such patterns have been extensively documented using satellite-measured outgoing longwave radiation (OLR) data as a proxy for tropical rainfall [e.g., Knutson and Weickmann, 1987; Rui and Wang, 1990].

[3] Following an analysis of the MSU-derived precipitation anomalies in the MJO [Bantzer and Wallace, 1996], Sperber [2003] analysed the MJO rainfall signal in the newly available pentad-mean version of the global gridded CMAP (merged satellite and gauge data) precipitation product [Xie and Arkin, 1997]. However, even though the primary characteristic of the MJO is its large-scale tropical rainfall anomalies, there have been relatively few studies of the MJO using raw rainfall data from meteorological stations, covering India [Hartmann and Michelsen, 1989; Singh et al., 1992; Krishnamurthy and Shukla, 2000], southwest Asia [Barlow et al., 2005], Australia and Indonesia [Wheeler and McBride, 2005], Africa [Mutai and Ward, 2000] and the western United States [Bond and Vecchi, 2003]. Such studies can be used to provide ground truth for the satellite products. Given that the station data are point measurements and the gridded satellite products are area averages, analysis of the station data can give extra information on the small-scale spatial variability and coherence of the rainfall patterns. Here, we present the first study of MJO rainfall anomalies over the western Pacific using station data.

\section{Data}

[4] The station rainfall data were daily totals from the Comprehensive Pacific Rainfall Data Base (PACRAIN [Morrissey et al., 1995]), available at http://www.evac. ou.edu/pacrain/. Stations were selected if they had at least 5 years of data, with less than $30 \%$ of days missing, giving a total of 140. All stations were at an altitude of $5 \mathrm{~m}$ or less, on low lying islands and atolls, and can be considered as representative of open ocean conditions. Due to the high spatial variability of rainfall and the point nature of individual stations, they were initially grouped into $10^{\circ} \times$ $10^{\circ}$ boxes to better capture the large-scale MJO variability. Even so, the spatial coverage over the western Pacific is highly variable; the maximum number of stations in one box is 21 , while several boxes only contained one station, and some had none (Figure 1a).

[5] Two satellite data sets with global coverage were also used to compare with the station data: (a) the daily mean interpolated OLR data set, based on NOAA AVHRR satellite measurements [Liebmann and Smith, 1996] is a well established proxy for tropical rainfall, (b) the pentad mean CMAP merged satellite-gauge rainfall data set [Xie and Arkin, 1997], which is mainly derived from the AVHRR data and provides more direct estimates of largescale rainfall.

[6] The MJO is at its most coherent during northern winter, hence the analysis was restricted to the 18 November-April seasons from $1979 / 80$ to $1996 / 97$. There is generally good agreement between climatological rainfall rate from the station data and the CMAP data (Figure 1b), especially where the station density is high. However, the CMAP climatological precipitation rate can vary by a factor of two over a single $10^{\circ} \times 10^{\circ}$ box, so boxes that only contain a few stations can show a systematic error if the locations of those stations are not evenly spread (e.g., the grid box at $\left.160-170^{\circ} \mathrm{E}, 10^{\circ} \mathrm{S}-0^{\circ} \mathrm{N}\right)$. Note it is not the intention here to create a consistent unbiased gridded product from the station data. Rather, we aim to see if the large-scale MJO rainfall anomalies in the satellite data set is at least qualitatively reproduced in the real, but limited, station data.

\section{MJO Composite Rainfall Cycle}

[7] The MJO cycle is defined by a standard technique, using the first two empirical orthogonal functions (EOFs) of 
(a) Number of stations

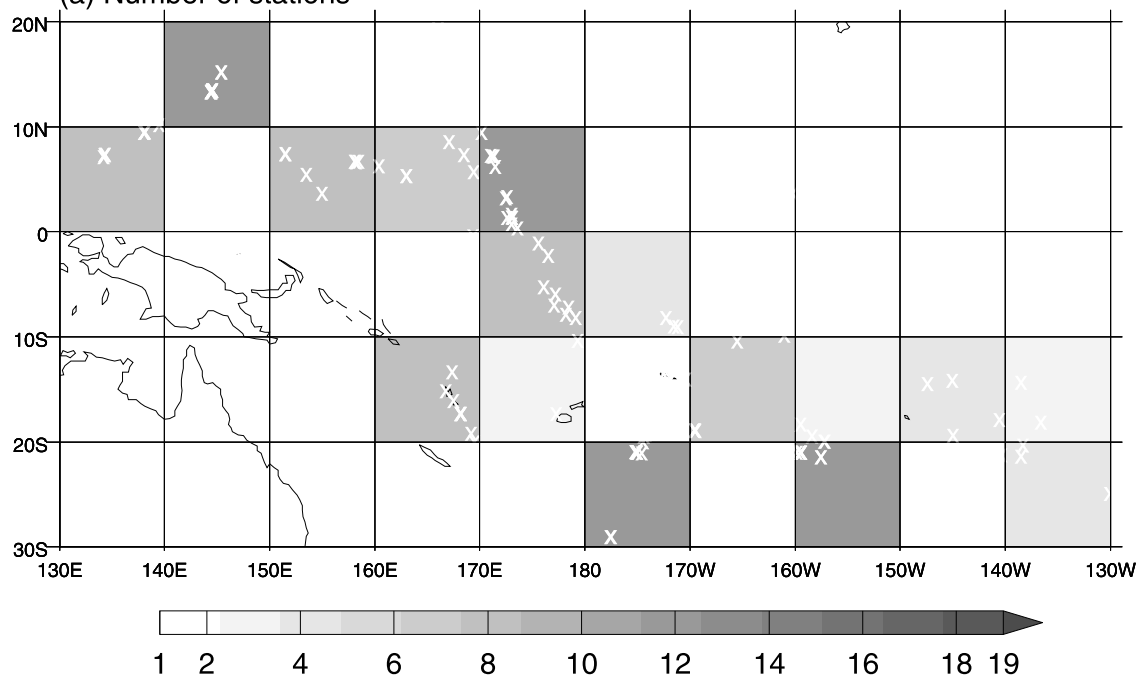

(b) Climatological rainfall rate

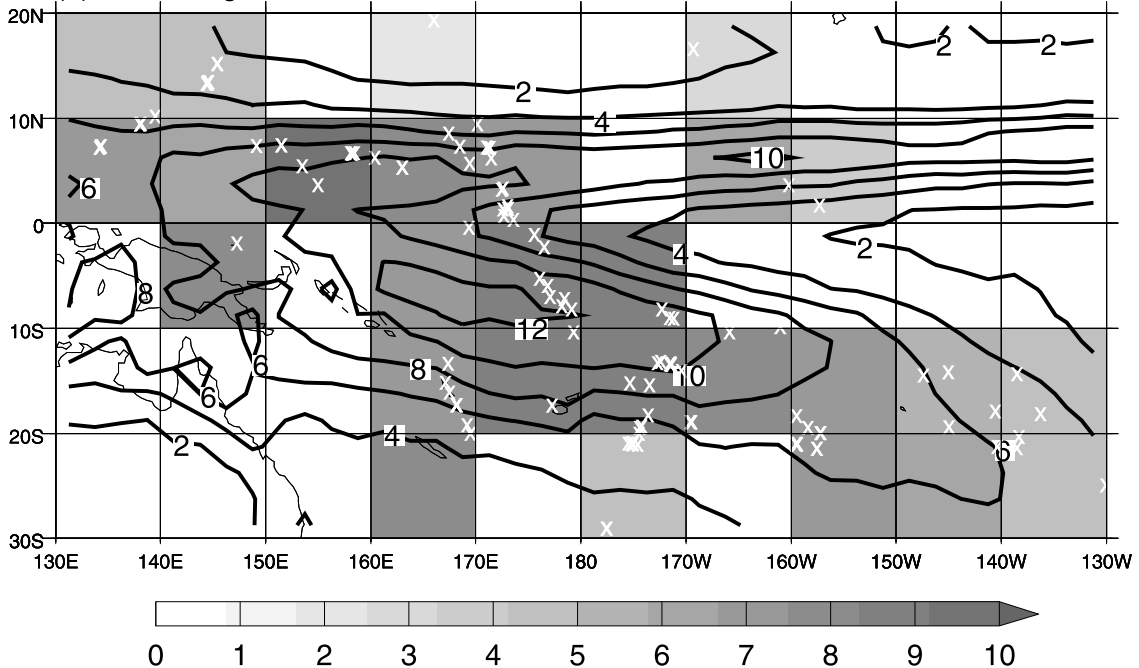

Figure 1. (a) The number of rainfall stations from the PACRAIN data set in each $10^{\circ} \times 10^{\circ}$ grid box is shown by the shading. Grid boxes with no rainfall stations are left white. The locations of the individual rainfall stations are shown by the white crosses. (b) November-April climatological mean station precipitation rate, averaged over $10^{\circ} \times 10^{\circ}$ grid boxes, is shown by the shading. The climatological mean CMAP precipitation rate is contoured with an interval of 2 mm day ${ }^{-1}$. See color version of this figure in the HTML.

intraseasonal (20-200-day) filtered OLR anomalies over the tropical belt. Individual days within the study period are then assigned to one of four MJO phases or categories (A$\mathrm{D})$, or a fifth category (NONE) if the MJO is inactive. Details of the exact method used here are described by Hall et al. [2001]. The MJO life cycle in OLR and CMAP precipitation anomalies shows the familiar behaviour. Negative OLR anomalies and enhanced precipitation over the Indian Ocean at the start of the MJO (category A; Figure 2a) propagate slowly eastward through categories B, C and D (Figures $2 b-2 d$ ) to the western Pacific.

[8] The MJO station rainfall anomalies over the PACRAIN study area are shown in Figure 3, together with the CMAP rainfall anomalies. The statistical significance of the station rainfall anomalies was established by comparing anomalies in opposite MJO phases (i.e., category A against $\mathrm{C}$, and $\mathrm{B}$ against $\mathrm{D}$ ) using a standard $t$-test. The station rainfall anomalies reproduce the overall CMAP precipitation patterns qualitatively, and the agreement is semi-quantitative where the station anomalies are statistically significant. Precipitation anomalies in the western Pacific in any one phase of the MJO have an amplitude of $1-3 \mathrm{~mm} \mathrm{day}^{-1}$. Hence, the difference between the opposite (wet minus dry) MJO phases is in the range $2-6 \mathrm{~mm}_{\text {day }}{ }^{-1}$, which is approximately $50 \%$ of the climatological values of 4-12 $\mathrm{mm} \mathrm{day}^{-1}$ (Figure 1b).

\section{Individual Stations}

[9] The station rainfall anomalies in Figure 3 were averaged over $10^{\circ} \times 10^{\circ}$ boxes for ease of presentation and to enable statistical significance to be calculated. However, the results are more illuminating when the individual station results are plotted. In category $A$, almost the 
(a) category $A$

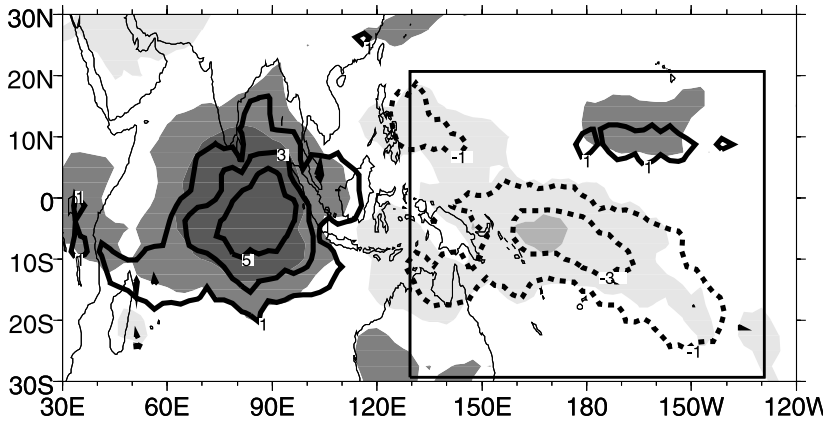

(b) category $B$

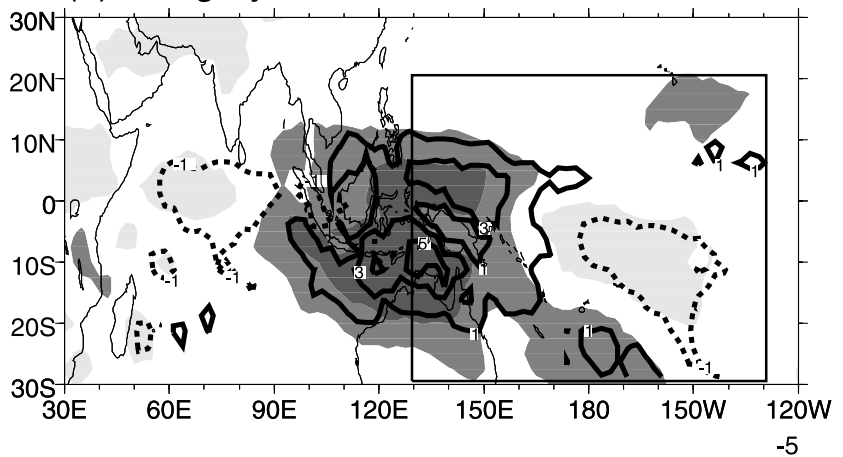

(c) category C

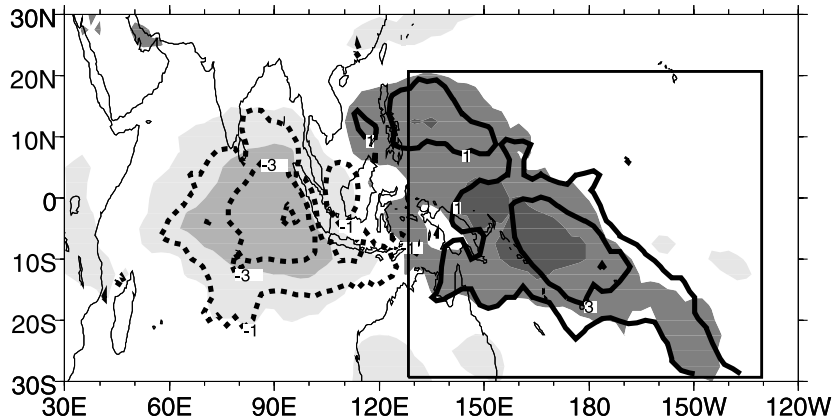

(d) category D

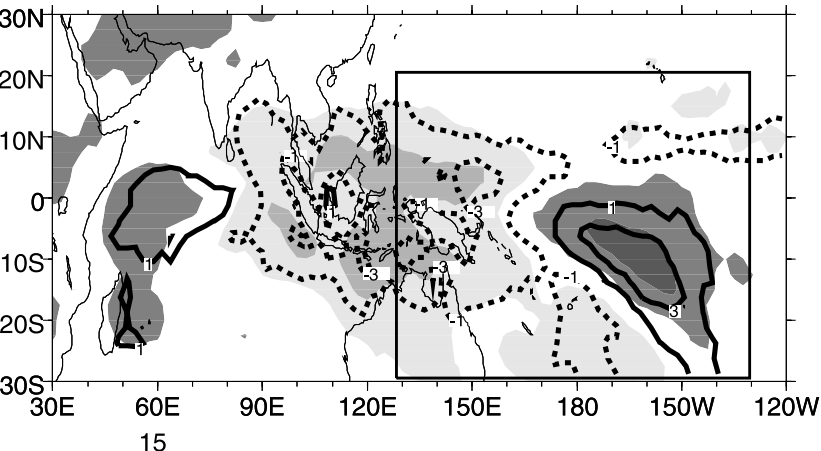

$-15$

Figure 2. Anomaly maps of OLR and CMAP precipitation for MJO category (a) A, (b) B, (c) C, (d) D. OLR anomalies below $-5 \mathrm{~W} \mathrm{~m}^{-2}$ are shaded darkly and anomalies above $5 \mathrm{~W} \mathrm{~m}^{-2}$ are shaded lightly; see legend. The CMAP contour interval is $2 \mathrm{~mm}$ day $^{-1}$ with the first positive/negative contours at $\pm 1 \mathrm{~mm}$ day $^{-1}$; negative contours are dotted. The rectangle over the western Pacific outlines the PACRAIN study area. See color version of this figure in the HTML. 
(a) category A

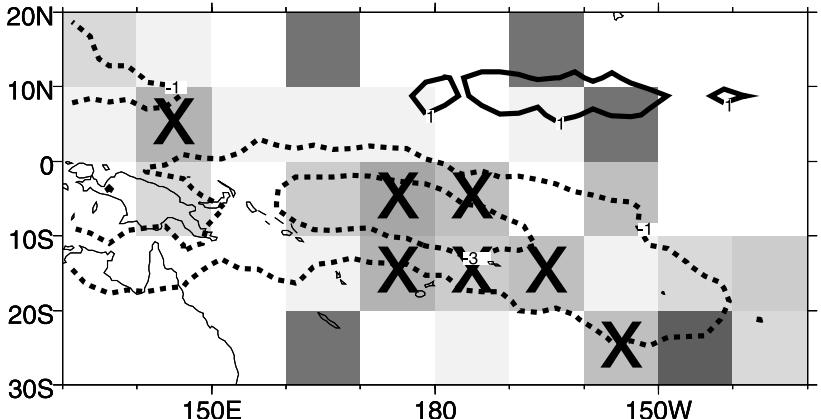

(b) category B

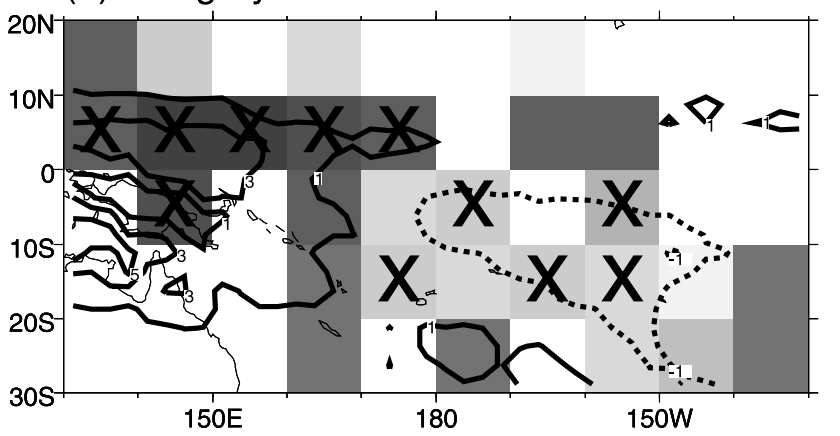

(c) category C

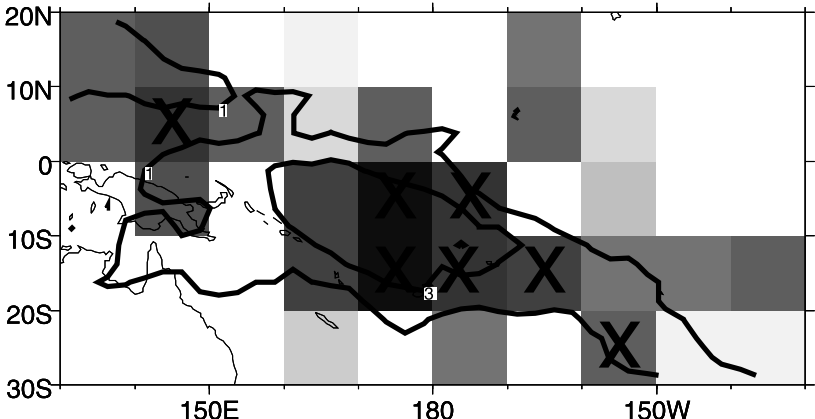

(d) category D

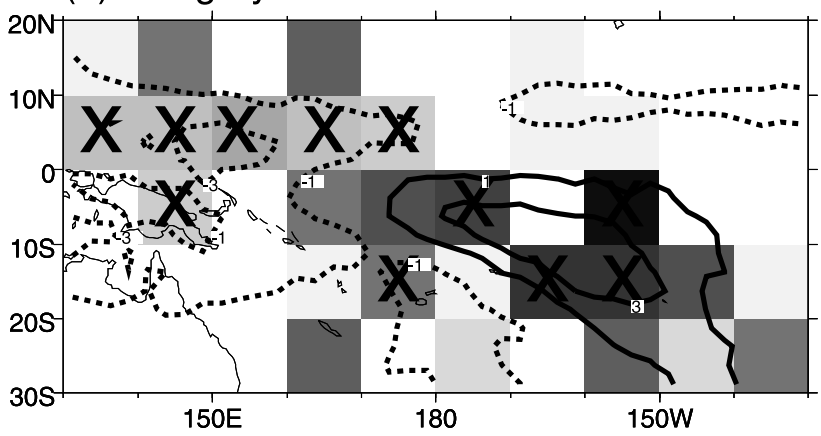

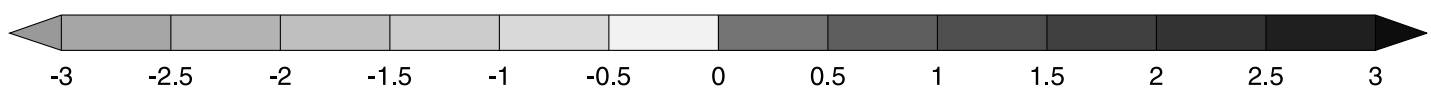

Figure 3. Maps of anomalous station precipitation averaged over $10^{\circ} \times 10^{\circ}$ grid boxes, and CMAP precipitation, for MJO category (a) A, (b) B, (c) C, (d) D. Negative station anomalies are shaded lightly and positive anomalies are shaded darkly; see legend. Grid boxes where the station precipitation is significantly different at the $95 \%$ level from that in the opposite MJO phase are shown by a cross at the centre of the grid box. The CMAP contour interval is $2 \mathrm{~mm}_{\text {day }}{ }^{-1}$ with the first positive/negative contours at $\pm 1 \mathrm{~mm}$ day $^{-1}$; negative contours are dotted. See color version of this figure in the HTML.

(a) category A

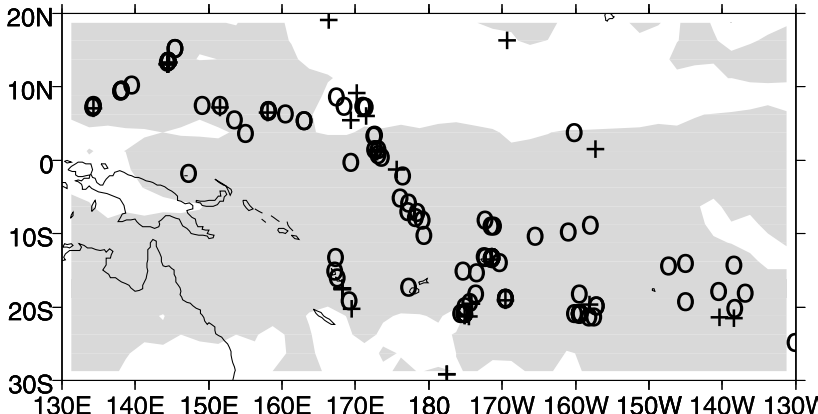

(b) category $\mathrm{B}$

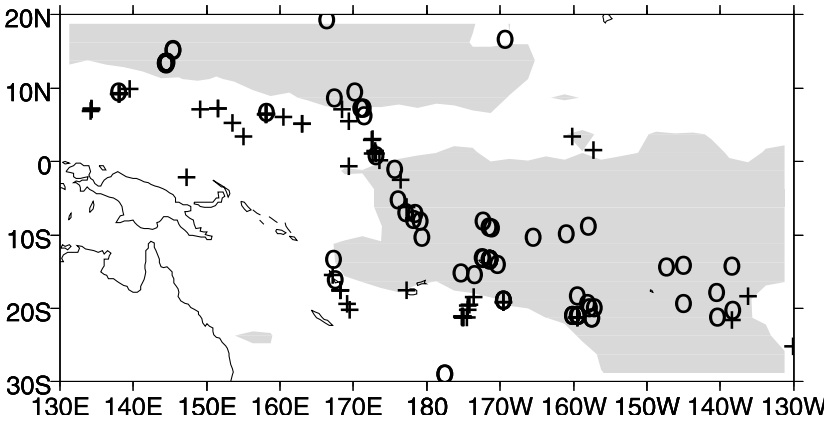

(c) category $\mathrm{C}$

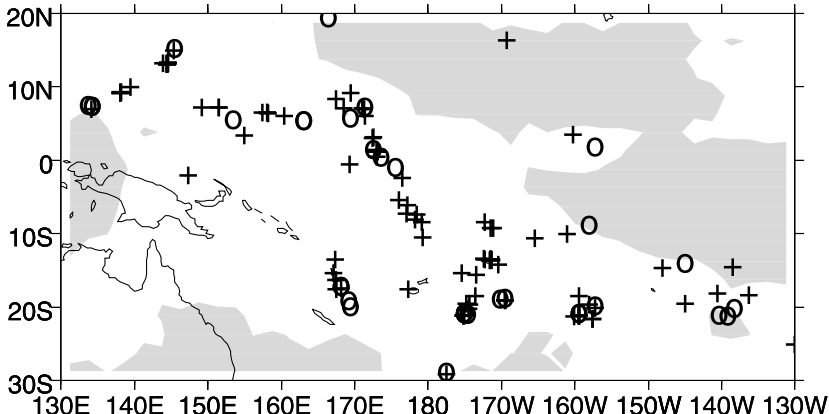

(d) category D

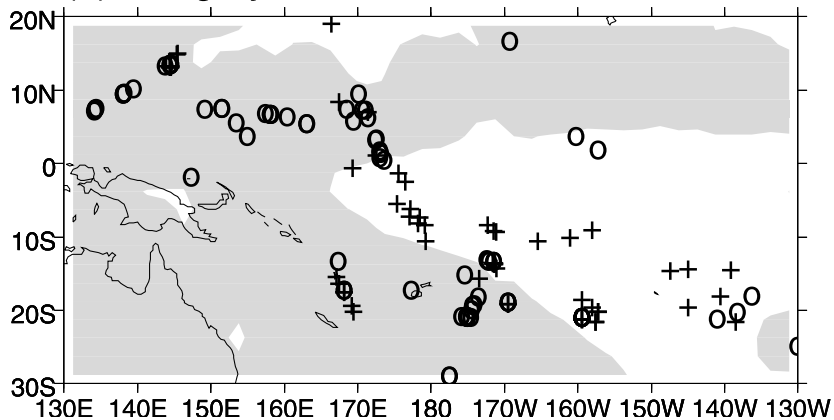

Figure 4. Sign of individual station precipitation anomalies for MJO category (a) A, (b) B, (c) C, (d) D. A plus indicates a positive anomaly, and a circle indicates a negative anomaly. Shading indicates regions of negative CMAP precipitation anomaly. See color version of this figure in the HTML. 
entire PACRAIN study area lies in the dry phase of the MJO, defined as the area of negative CMAP rainfall anomalies, and shaded in Figure 4. Within this region, 99 stations show a dry anomaly while only 17 show a wet anomaly (Figure $4 \mathrm{a}$ ). Hence, $86 \%$ of the point rainfall measurements at individual stations are in accord with the overall large-scale rainfall pattern. This figure is more remarkable as all stations have been included, whether they or their corresponding CMAP rainfall anomalies are statistically significant or not.

[10] Similarly, in category $\mathrm{C}$, the western Pacific is in the wet phase of the $\mathrm{MJO}$, and the overwhelming majority $(77 \%)$ of the individual stations record wet conditions too (Figure 4c). In the intermediate categories B and D (Figures $4 \mathrm{~b}$ and $4 d$ ), there is again a very strong relationship between the sign of the individual station rainfall anomalies and the sign of the large-scale pattern.

\section{Conclusions}

[11] The MJO rainfall signal over the western Pacific can clearly be identified in raw station data. Typical wet minus dry phase anomalies are in the range $2-6 \mathrm{~mm}_{\text {day }}{ }^{-1}$, compared to climatological values in the range 4-12 $\mathrm{mm}_{\text {day }}{ }^{-1}$. Although the station data has not been formally gridded, it compares well with and ground truths recently available pentad-mean gridded precipitation products that are mainly based on satellite data. In addition, the station data show the spatial coherence of the MJO rainfall signal, as approximately $80 \%$ of the individual point stations have the same sign rainfall anomaly as the large-scale signal from the satellite data.

[12] Acknowledgments. The rainfall data were provided through the PACRAIN project (http://www.evac.ou.edu/pacrain/). The OLR and CMAP data were provided through the NOAA Climate Diagnostics Center (http:// www.cdc.noaa. gov).

\section{References}

Bantzer, C. H., and J. M. Wallace (1996), Intraseasonal variability in tropical mean temperature and precipitation and their relation to the tropical 40-50 day oscillation, J. Atmos. Sci., 53, 3032-3045.

Barlow, M., et al. (2005), Modulation of daily precipitation over southwest Asia by the Madden-Julian oscillation, Mon. Weather Rev., 133, in press. Bond, N. A., and G. A. Vecchi (2003), The influence of the Madden-Julian oscillation on precipitation in Oregon and Washington, Wea. Forecasting, $18,600-613$

Hall, J. D., et al. (2001), The modulation of tropical cyclone activity in the Australian region by the Madden-Julian oscillation, Mon. Weather Rev., 129, 2970-2982.

Hartmann, D. L., and M. L. Michelsen (1989), Intraseasonal periodicities in Indian rainfall, J. Atmos. Sci., 46, 2838-2862.

Knutson, T. R., and K. M. Weickmann (1987), 30-60 day atmospheric oscillations: Composite life cycles of convection and circulation anomalies, Mon. Weather Rev., 115, 1407-1436.

Krishnamurthy, V., and J. Shukla (2000), Intraseasonal and interannual variability of rainfall over India, J. Clim., 13, 4366-4377.

Liebmann, B., and C. A. Smith (1996), Description of a complete (interpolated) OLR dataset, Bull. Am. Meteorol. Soc., 77, 1275-1277.

Madden, R. A., and P. R. Julian (1994), Observations of the 40-50 day tropical oscillation-A review, Mon. Weather Rev., 122, 814-837.

Morrissey, M. L., et al. (1995), The Pacific rain-gauge rainfall database, Water Resour. Res., 31, 2111-2113.

Mutai, C. C., and M. N. Ward (2000), East African rainfall and the tropical circulation/convection on intraseasonal to interannual timescales, J. Clim., 13, 3915-3939.

Rui, H., and B. Wang (1990), Development characteristics and dynamic structure of tropical intraseasonal convective anomalies, J. Atmos. Sci., 47, 357-379.

Singh, S. V., et al. (1992), Interannual variability of the Madden-Julian oscillations in Indian-summer monsoon rainfall, J. Clim., 5, 973-978.

Sperber, K. R. (2003), Propagation and the vertical structure of the Madden-Julian oscillation, Mon. Weather Rev., 131, 3018-3037.

Wheeler, M., and J. L. McBride (2005), Australian-Indonesian monsoon, in Intraseasonal Variability in the Atmosphere-Ocean Climate System, edited by W. K. M. Lau and D. E. Waliser, pp. 125-173, Springer, New York.

Xie, P., and P. A. Arkin (1997), Global precipitation: A 17-year monthly analysis based on gauge observations, satellite estimates, and numerical model outputs, Bull. Am. Meteorol. Soc., 78, 2539-2558.

H. Y. Y. Li and A. J. Matthews, School of Environmental Sciences, University of East Anglia, Norwich NR4 7TJ, UK. (a.j.matthews@uea. ac.uk) 